\title{
COMPARATIVE EVALUATION OF THE EFFECT OF ANTIOXIDANTS IN THE CONSERVATION OF RAM SEMEN
}

\author{
P. SARLÓs*, A. MOLNÁR, M. KóKAI, Gy. GÁBOR and J. RÁtKY \\ Research Institute for Animal Breeding and Nutrition, H-2053 Herceghalom, \\ Gesztenyés u. 1, Hungary
}

(Received October 30, 2001; accepted December 13, 2001)

\begin{abstract}
The aim of the present study was to develop a treatment supporting the membrane of ram spermatozoa. Semen of different ejaculates collected from breeding rams was mixed and samples of $10^{9}$ sperm cells per $\mathrm{ml}$ and Tris-egg yolk extender were completed with the following antioxidants: $\alpha$-tocopherol acetate (E), glutathione peroxidase (GP), Aromex ${ }^{\circledR}(\mathrm{AR})$, resveratrol (R), resveratrol + vitamin E (RE), resveratrol + Aromex $^{\circledR}$ (RAR), resveratrol + GP (RGP). Peroxidation was evaluated by the analysis of malondialdehyde (MDA) during incubation for 30,60 and $120 \mathrm{~min}$ at $37^{\circ} \mathrm{C}$ as well as during a $24-\mathrm{h}$ incubation at $5{ }^{\circ} \mathrm{C}$. The success of preservation was checked in a 9-day-long period by observing the acrosomal defects and the motility of spermatozoa. Concentration of MDA was $4.06 \mathrm{nmol} / 10^{9}$ spermatozoa in samples treated with $15 \mu \mathrm{g} \mathrm{R}$ while the control sample contained $69.79 \mathrm{nmol}$ MDA per $10^{9}$ spermatozoa after 24-h incubation. Following 30-, 60- and 120-min storage the concentration of MDA in control and R-treated samples was $25.89,36.91,49.57$ and $3.69,3.74,3.74 \mathrm{nmol} / 10^{9}$ spermatozoa, respectively. Moreover, a significantly higher proportion of motile sperm cells was observed in the treated than in the control samples. The frequency of acrosomal defects was lower in the treated groups than in the control. These results indicate that RAR treatment can improve the effects of ram semen preservation.
\end{abstract}

Key words: Ram semen, antioxidant, conservation, sperm motility, acrosomal damage

Conservation of the fertilising capacity of fresh semen for the longest possible time is essential in the practice of artificial insemination for all farm animal species including sheep. A basic problem with the conservation of ram semen is the high unsaturated fatty acid content of the membrane of spermatozoa. These unsaturated fatty acids tend to bind oxygen, which results in the formation of numerous peroxide bonds. These undesired peroxidation processes result in disruption of the sperm cell membrane and consequently impair the fertilising capacity of semen.

*Corresponding author; E-mail: atk@atk.hu; Fax: +36 (23) 319133 
Lipid peroxidation induced by reactive oxygen compounds directly damages the phospholipid components of cell membranes, and the reactive groups can exert an effect at sites distant from the site of radical formation (Cheeseman, 1993). In the terminal phase of this process stable compounds (such as malondialdehyde) are formed, which have genotoxic effect (Burcham, 1998). The spontaneous lipid peroxidation of mammalian spermatozoa damages the lipid matrix, which is related to the impairment of sperm motility (Jones and Mann, 1976, 1977a, 1977b).

During the processing of semen, lipid peroxidation can be effectively inhibited by providing an anaerobic environment; however, this is technically not feasible (Milovanov et al., 1976; Shajdullin, 1977; Varnavskij and Varnavskaja, 1980). Complete prevention of lipid peroxidation is difficult, as this reaction utilises products generated by the basic metabolic processes (Hammerstedt, 1993).

In vitro studies have shown that antioxidant treatment improves the survival and motility of bull spermatozoa (Shannon and Curson, 1982; Vishwanath et al., 1994), as well as the motility and penetration capacity of human spermatozoa (Jones et al., 1978; Aitken and Clarkson, 1988) during liquid storage.

The best-known antioxidant compound is $\alpha$-tocopherol (vitamin E). Tocopherols in general, including $\alpha$-tocopherol, are lipophilic antioxidants which reduce oxygen free radicals in a hydrophobic environment (Diplock and Lucy, 1973).

In some experiments tocopherol was the most effective when sucrosebased semen extenders containing glucose, EDTA-Na $\mathrm{Na}_{2}$ complex and Tris buffer were used and the semen was processed under aerobic conditions (Varnavskij and Varnavskaja, 1976, 1978; Milovanov et al., 1976). Upreti et al. (1997) studied the effect of five antioxidants - vitamin E, butylated hydroxyanisole (BHA), n-propyl gallate (n-PG), deferoxamine mesylate (Desferal) and catalase - on the motility of ram spermatozoa in RSD-1 ram semen extender.

According to experimental findings, when the semen was treated with superoxide dismutase (SOD), catalase (CAT), cytochrome c (Chc) and glutathione peroxidase (GP), all these substances improved sperm motility and acrosome integrity, and a linear increase was found in the survival of spermatozoa if the concentration of antioxidants was increased (Maxwell and Stojanov, 1996). According to Witting (1980), SOD, CAT and GP are the primary components of the defence mechanism against reactive oxygen compounds.

The ram ejaculate contains detectable quantities of superoxide dismutase and somewhat lower amounts of glutathione peroxidase and catalase (AbuErreish et al., 1978; Mann and Lutwak-Mann, 1981), but the concentration of these enzymes markedly decreases when the semen is diluted.

Studies on bovine sperm revealed a close, statistically significant correlation between malondialdehyde production and SOD activity (Beconi et al., 1991). 
According to experimental results, age-related changes of phospholipid composition are associated with a decrease in the main antioxidant enzyme systems in the seminal plasma (SOD, GP) (Kelso et al., 1997).

This paper reports an experiment aimed at improving the conservation of ram semen during liquid storage. In this experiment the protective efficacy of different antioxidants and their mixtures against reactive oxygen radicals was studied. In addition to compounds that had been in use for some time, the effect of two antioxidants hitherto not used in semen conservation was studied.

\section{Materials and methods}

Using an artificial vagina, semen was collected from five mature, 1.5year-old British Milk rams twice a week. The fresh ejaculates were examined for sperm motility by light microscopy. Motility was scored on a scale from 1 to 5 . The morphology of spermatozoa was examined in stained smears (Cerovsky, $1976)$ at a magnification of $\times 1000$. Ejaculates with a motility score $<4$ and containing abnormal spermatozoa at a ratio $>20 \%$ were excluded from the further experiments.

Ejaculates judged to be suitable for further experimentation on the basis of motility and morphological examinations were pooled. The sperm concentration of pooled semen was measured with the help of a Buerker chamber.

In the first experiments, lipid peroxidation was measured in treated and untreated (control) semen samples in induced reactions. For the measurement, the semen was diluted with an equivalent volume of Krebs-Ringer solution (Mann, 1964) and centrifuged. After a single washing, samples with $10^{9}$ spermatozoa/ml were prepared and treated with different concentrations of antioxidants: $\alpha$-tocopherol acetate (E) (vitamin E acetate, Sigma Chemical Co., St. Louis, MO, USA) $0.5,1,2.5,5 \mathrm{mg} / 10^{9}$ spermatozoa $/ \mathrm{ml}$; glutathione peroxidase (GP) (Sigma Chemical Co., St. Louis, MO, USA) 1, 5, 10, 15 U/109 spermato$\mathrm{zoa} / \mathrm{ml}$; Aromex ${ }^{\circledR}$ (AR) (Delacon $\mathrm{GmbH}$, Steyregg, Austria) 0.05, 0.1, 0.2, 0.3, $0.5 \mathrm{mg} / 10^{9}$ spermatozoa/ml; 3,4',5-trihidroxy-stilbene (R) (resveratrol, Sigma Chemical Co., St. Louis, MO, USA) 2.5, 5, 10, 15, $20 \mu \mathrm{g} / 10^{9}$ spermatozoa $/ \mathrm{ml}$. In a further experiment, antioxidant mixtures containing resveratrol as a constant component were added to semen samples containing $10^{9}$ spermatozoa $/ \mathrm{ml}: 15 \mu \mathrm{g}$ $\mathrm{R}+5 \mathrm{mg}$ E (RE), $15 \mu \mathrm{g} \mathrm{R}+0.5 \mathrm{mg}$ AR (RAR), $15 \mu \mathrm{g} \mathrm{R}+15 \mathrm{U}$ GP (RGP).

The treated and control samples $\left(10^{9}\right.$ spermatozoa $\left./ \mathrm{ml}\right)$ were incubated in the presence of $0.2 \mathrm{mg}$ sodium ascorbate and $0.5 \mathrm{mmol}$ ferrous sulphate at $37^{\circ} \mathrm{C}$ for $120 \mathrm{~min}$ or kept at $5^{\circ} \mathrm{C}$ for $24 \mathrm{~h}$. Lipid peroxidation was measured by the spectrophotometric method of Placer et al. (1966) as modified by Dorman et al. (1995), which is based on the reaction of the lipid peroxidation end product malondialdehyde (MDA) and thiobarbituric acid (TBA). The samples incubated at 
$37^{\circ} \mathrm{C}$ were measured by photometry at $532 \mathrm{~nm}$ after 30,60 and $120 \mathrm{~min}$, while those kept at $5{ }^{\circ} \mathrm{C}$ after $24 \mathrm{~h}$.

In further experiments, the pooled semen was diluted with Tris-glucoseegg yolk (TGY) semen extender: $300 \mathrm{mmol}$ Tris (hydroxymethyl) aminomethane, $94.72 \mathrm{mmol}$ citric acid, $27.78 \mathrm{mmol}$ glucose, $15 \%$ egg yolk and $70 \mu \mathrm{g} / \mathrm{ml}$ gentamycin. Samples containing $10^{9}$ spermatozoa per $\mathrm{ml}$ were prepared, to which antioxidant ' $R$ ' and mixtures containing antioxidant ' $R$ ' were added: $15 \mu \mathrm{g} \mathrm{R}+5 \mathrm{mg}$ E (RE), $15 \mu \mathrm{g} \mathrm{R}+0.5 \mathrm{mg}$ AR (RAR), $15 \mu \mathrm{g}$ R. The treated and the control samples were kept at $5{ }^{\circ} \mathrm{C}$ for 9 days. During the conservation test, sperm motility was checked with the help of a computer on days 1,2 , 3, 6, 8 and 9 (Gábor and Szász, 2000), and membrane integrity was examined after acrosome staining (Kovács and Foote, 1992) at $\times 1000$ magnification.

During statistical evaluation of the data the antioxidant treatments were compared by the $t$-test.

\section{Results}

On increasing the amount of antioxidants, the MDA concentration of the samples incubated at $37^{\circ} \mathrm{C}$ and of those kept at $5{ }^{\circ} \mathrm{C}$ decreased. The lowest values were obtained for the following antioxidant quantities: E $5 \mathrm{mg}$, GP $15 \mathrm{U}$, AR $0.5 \mathrm{mg}$, R $15 \mu \mathrm{g} / 10^{9}$ spermatozoa/ml (Fig. 1).

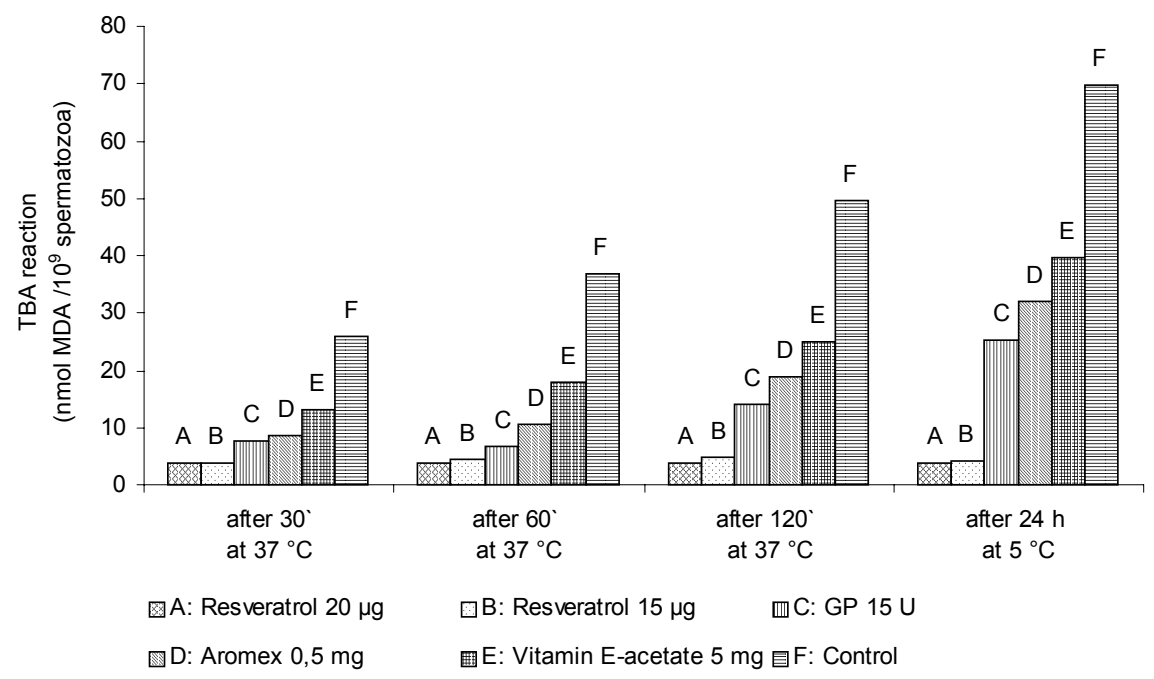

Fig. 1. Change of malondialdehyde concentration in semen samples treated with different antioxidants after incubation at $37^{\circ} \mathrm{C}$ and keeping at $5{ }^{\circ} \mathrm{C}$

Antioxidant $\mathrm{R}$ was the most effective both in samples incubated at $37^{\circ} \mathrm{C}$ and in those kept at $5{ }^{\circ} \mathrm{C}$. Only a negligible difference was found in MDA con- 
centration between semen samples treated with $15 \mu \mathrm{g}$ and those treated with $20 \mu \mathrm{g}$ antioxidant $\mathrm{R}$. In the control samples kept at $5^{\circ} \mathrm{C}$ for $24 \mathrm{~h} 69.79 \mathrm{nmol}$ MDA $/ 10^{9}$ spermatozoa was measured. In the presence of $15 \mu \mathrm{g} R$ the measured MDA concentration was $4.06 \mathrm{nmol} / 10^{9}$ spermatozoa. During incubation for 120 min the MDA concentration was found to increase in the control semen samples: the concentrations measured after 30,60 and 120 minutes were 25.89, 36.91 and $49.57 \mathrm{nmol}$, respectively. The MDA content of samples containing antioxidant $\mathrm{R}$ was nearly identical, i.e. $3.69,3.74$ and $3.74 \mathrm{nmol}$ at the above times. An elevation of MDA content was observed also in samples containing E, GP and AR. The weakest antioxidant effect was observed in samples containing E, with MDA concentrations of $22.63,32.12$ and $41.80 \mathrm{nmol} / 10^{9}$ spermatozoa after incubation at $37^{\circ} \mathrm{C}$ and $56.31 \mathrm{nmol} / 10^{9}$ spermatozoa after keeping at $5{ }^{\circ} \mathrm{C}$.

Like in the previous experiment, in the experiment performed with antioxidant mixtures the MDA content of control samples increased during incubation at $37^{\circ} \mathrm{C}$ : after 30,60 and $120 \mathrm{~min} 25.63,36.22$ and 46.09 nmol concentrations were measured, respectively. In samples treated with $\mathrm{R}$ or with antioxidant mixtures MDA concentrations below $4.1 \mathrm{nmol} / 10^{9}$ spermatozoa were found at all three time-points.

After 24-h storage at $5^{\circ} \mathrm{C}$, similar MDA concentrations were measured in the antioxidant-supplemented samples: 2.75 (RGP), 3.04 (R), 3.17 (RE) and $3.31 \mathrm{nmol}$ (RAR). The average MDA concentration was $3.06 \mathrm{nmol} / 10^{9}$ spermatozoa. The MDA concentration measured in the control samples was 12.6 times higher, $38.58 \mathrm{nmol} / 10^{9}$ spermatozoa (Fig. 2).

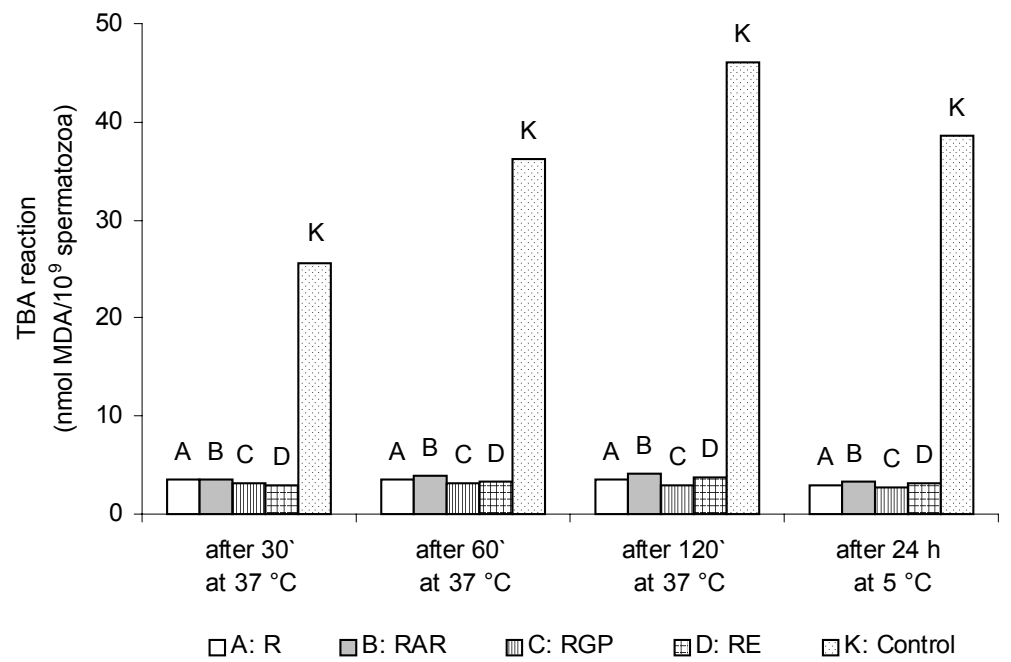

Fig. 2. Change of malondialdehyde concentration in semen samples treated with antioxidant mixtures after incubation at $37^{\circ} \mathrm{C}$ and keeping at $5{ }^{\circ} \mathrm{C}$ 
The results of the 9-day semen conservation experiment are summarised in Table 1 . The quality of semen deteriorated during storage irrespective of the treatments. Motility decreased and the ratio of spermatozoa with membrane damage increased. The treated samples were characterised by a lower ratio of damaged spermatozoa and the conservation of semen improved. Compared to 0$h$ values, on the third day of conservation the control semen samples had significantly lower motility $(\mathrm{P} \leq 0.01)$. In samples treated with $\mathrm{R}, \mathrm{RAR}$ or $\mathrm{RE}$ a significant decrease $(\mathrm{P} \leq 0.05)$ in the ratio of motile spermatozoa occurred only from day 6 . After the third day the ratio of motile spermatozoa was markedly higher in the antioxidant-containing samples: significant differences from the control samples were observed on day 6 for $\mathrm{R}(\mathrm{P} \leq 0.001)$, on day 8 for RAR $(\mathrm{P} \leq 0.001)$, and on day 9 for RAR $(P \leq 0.001)$ and $R(P \leq 0.05)$. On day 9 the highest motility ratio $(53 \%)$ was measured in the sample containing RAR. That value exceeded the motility of the control semen $(18.5 \%)$ by more than $30 \%$.

\section{Table 1}

Change of sperm motility in semen samples treated with antioxidant mixtures during storage at $5{ }^{\circ} \mathrm{C}$ for 9 days (\%)

\begin{tabular}{|c|c|c|c|c|c|c|c|c|}
\hline \multirow{4}{*}{ Day } & \multicolumn{8}{|c|}{ Semen samples } \\
\hline & \multirow{2}{*}{\multicolumn{2}{|c|}{$\frac{\text { Control }}{\text { Motility }}$}} & \multirow{2}{*}{\multicolumn{2}{|c|}{$\frac{\text { RAR }}{\text { Motility }}$}} & \multirow{2}{*}{\multicolumn{2}{|c|}{$\frac{\mathrm{RE}}{\text { Motility }}$}} & \multirow{2}{*}{\multicolumn{2}{|c|}{$\frac{\mathrm{R}}{\text { Motility }}$}} \\
\hline & & & & & & & & \\
\hline & Mean & SD & Mean & SD & Mean & SD & Mean & $\mathrm{SD}$ \\
\hline 0 & 77.5 & 4.92 & - & - & - & - & - & - \\
\hline 1 & 78.3 & 12.89 & 79.0 & 15.52 & 72.3 & 13.01 & 85.0 & 3.46 \\
\hline 2 & 78.0 & 6.00 & 74.6 & 1.15 & 73.6 & 11.37 & 75.3 & 11.06 \\
\hline 3 & 58.5 & 6.50 & 64.5 & 4.50 & 59.5 & 7.50 & 56.5 & 12.50 \\
\hline 6 & 39.0 & 9.00 & 57.5 & 0.50 & 60.0 & 2.00 & $51.5^{* * *}$ & 9.50 \\
\hline 8 & 36.5 & 15.50 & $64.5^{* * *}$ & 14.50 & 55.0 & 8.00 & 48.5 & 1.52 \\
\hline 9 & 18.5 & 11.50 & $53.0^{* * *}$ & 12.00 & 45.0 & 10.00 & $42.5^{*}$ & 3.53 \\
\hline
\end{tabular}

$\mathrm{RAR}=$ resveratrol + Aromex $; \mathrm{RE}=$ resveratrol + vitamin $\mathrm{E}$ acetate $; \mathrm{R}=$ resveratrol; ${ }^{*} \mathrm{P} \leq 0.05$, **** $\mathrm{P} \leq 0.001$

From day 2 of storage, the ratio of cells with acrosomal damage increased significantly in the control samples $(\mathrm{P} \leq 0.01-0.001)$, in samples containing RAR $(\mathrm{P} \leq 0.01)$ and in those containing RE $(\mathrm{P} \leq 0.05-0.001)$. In semen samples containing antioxidant $\mathrm{R}$ a significant difference from the 0 -hour value was observed on day $8(\mathrm{P} \leq 0.01)$ and day $9(\mathrm{P} \leq 0.001)$.

The ratio of spermatozoa with acrosomal damage was higher in the control samples throughout the period of storage. In this respect, significant differences from the treated semen samples were found on days 6,8 and $9(\mathrm{P} \leq 0.001, \mathrm{P} \leq$ 0.01 and $\mathrm{P} \leq 0.05$, respectively) (Table 2 ). 
Table 2

Differences in the ratio of spermatozoa with acrosomal damage between control and antioxidanttreated semen samples during 9-day storage at $5^{\circ} \mathrm{C}(\%)$

\begin{tabular}{|c|c|c|c|c|c|c|c|c|}
\hline \multirow{4}{*}{ Day } & \multicolumn{8}{|c|}{ Semen samples } \\
\hline & \multicolumn{2}{|c|}{ Control } & \multicolumn{2}{|c|}{ RAR } & \multicolumn{2}{|c|}{$\mathrm{RE}$} & \multicolumn{2}{|c|}{$\mathrm{R}$} \\
\hline & \multicolumn{2}{|c|}{ Acrosomal damage } & \multicolumn{2}{|c|}{ Acrosomal damage } & \multicolumn{2}{|c|}{ Acrosomal damage } & \multicolumn{2}{|c|}{ Acrosomal damage } \\
\hline & Mean & SD & Mean & SD & Mean & SD & Mean & SD \\
\hline 0 & 20.7 & 4.89 & - & - & - & - & - & - \\
\hline 1 & 27.8 & 6.21 & 24.6 & 3.72 & 24.0 & 6.29 & 22.5 & 4.37 \\
\hline 2 & 28.3 & 5.04 & 26.6 & 4.27 & 31.8 & 3.06 & 26.8 & 8.31 \\
\hline 3 & 37.2 & 5.03 & 28.2 & 5.56 & 36.8 & 4.32 & 30.6 & 4.15 \\
\hline 6 & 49.5 & 3.10 & $30.2^{* *}$ & 3.83 & $37.6^{*}$ & 3.91 & $28.6^{* * *}$ & 3.57 \\
\hline 8 & 52.6 & 5.17 & $35.2^{* *}$ & 5.54 & $40.6^{*}$ & 6.54 & $36.6^{* *}$ & 5.31 \\
\hline 9 & 54.0 & 3.53 & $35.8^{* *}$ & 1.78 & $42.2^{*}$ & 8.58 & $40.2^{*}$ & 4.70 \\
\hline
\end{tabular}

$\mathrm{RAR}=$ resveratrol + Aromex; $\mathrm{RE}=$ resveratrol + vitamin $\mathrm{E}$ acetate; $\mathrm{R}=$ resveratrol; ${ }^{*} \mathrm{P} \leq 0.05$, ${ }^{* *} \mathrm{P} \leq 0.01,{ }^{* * *} \mathrm{P} \leq 0.001$

By the end of the conservation experiment the ratio of spermatozoa with acrosomal damage increased by further $33.3 \%$ in the untreated semen samples, as compared to the $20.7 \%$ found for fresh semen. In samples treated with RAR a $15.1 \%$ increase was seen, and $35.8 \%$ of the spermatozoa showed acrosomal damage. The other antioxidants also provided substantial protection against membrane damage. Compared to fresh semen, sperm motility was, in average, $59.0 \%$ lower in the control samples and $24.5 \%, 32.5 \%$ and $35.0 \%$ lower in the samples treated with antioxidants RAR, RE and R (Table 3).

\section{Table 3}

Change of sperm motility and the ratio of acrosomal damage in untreated and treated semen samples during 9-day storage at $5{ }^{\circ} \mathrm{C}$, as compared to values measured in fresh semen (\%)

\begin{tabular}{|c|c|c|c|c|c|c|c|c|}
\hline \multirow{3}{*}{ Day } & \multicolumn{8}{|c|}{ Semen samples } \\
\hline & \multicolumn{2}{|c|}{ Control } & \multicolumn{2}{|c|}{ RAR } & \multicolumn{2}{|c|}{ RE } & \multicolumn{2}{|c|}{$\mathrm{R}$} \\
\hline & Motility & $\begin{array}{c}\text { Acrosomal } \\
\text { damage }\end{array}$ & Motility & $\begin{array}{c}\text { Acrosomal } \\
\text { damage }\end{array}$ & Motility & $\begin{array}{c}\text { Acrosomal } \\
\text { damage }\end{array}$ & Motility & $\begin{array}{c}\text { Acrosomal } \\
\text { damage }\end{array}$ \\
\hline 1 & +0.8 & +7.1 & +1.5 & +3.9 & -5.2 & +3.4 & +7.5 & +1.8 \\
\hline 2 & +0.5 & +7.6 & -2.9 & +5.9 & -3.9 & +11.1 & -2.2 & +6.1 \\
\hline 3 & -19.0 & +16.5 & -13.0 & +7.5 & -18.0 & +16.1 & -21.0 & +9.9 \\
\hline 6 & -38.5 & +28.8 & -20 & +9.5 & -17.5 & +16.9 & -26.0 & +7.9 \\
\hline 8 & -41.0 & +31.9 & -13.0 & +14.5 & -22.5 & +19.9 & -29.0 & +15.9 \\
\hline 9 & -59.0 & +33.3 & -24.5 & +15.1 & -32.5 & +21.5 & -35.0 & +19.5 \\
\hline
\end{tabular}

$\mathrm{RAR}=$ resveratrol + Aromex $\mathrm{RE}=$ resveratrol + vitamin $\mathrm{E}$ acetate $\mathrm{R}=$ resveratrol 


\section{Discussion}

The results demonstrate that the antioxidants used in the experiment inhibited lipid peroxidation to a different extent and, thus, they differ in efficacy.

Protection can be enhanced by increasing the concentration of antioxidants. In this work, after treatment of semen samples with 15 or $20 \mu \mathrm{g}$ resveratrol (R) only negligible differences were found in their MDA concentration (Fig. 1). The lowest MDA values were measured in samples treated with antioxidant $\mathrm{R}$ and with the antioxidant mixtures containing $\mathrm{R}$ in the case of both the samples incubated at $37^{\circ} \mathrm{C}$ and those kept at $5^{\circ} \mathrm{C}$ (Figs 1 and 2).

The incubation time influences the TBA reaction. Jones and Mann (1976) demonstrated that the concentration of MDA increased in ram semen incubated at $37^{\circ} \mathrm{C}$. Also in the present experiment, an elevation in MDA concentration was observed in samples treated with E, GP or AR and in the control samples during a 120 -min incubation. The values measured in the treated samples was lower than those of the control samples at all measuring times. The MDA content of samples R, RGP, RAR and RE was always nearly identical (3.69-4.01 nmol), which demonstrates the decisive role played by resveratrol in the antioxidant mixtures.

Figure 1 shows that $\alpha$-tocopherol acetate (E) provided the weakest protection against reactive oxygen radicals. In contrast, in experiments performed with good-quality samples of deep-frozen bovine semen $\alpha$-tocopherol acetate gave significant protection against lipid peroxidation (Beconi et al., 1993). Nauk and Boronchuk (1992) also reported significantly lower MDA content in deep-frozen ram semen as a result of treatment with $\alpha$-tocopherol acetate. In the present studies, treatment with $5 \mathrm{mg} \alpha$-tocopherol acetate did not cause a marked decrease in MDA concentration after 1-hour incubation ( $32.12 \mathrm{nmol} / 10^{9}$ spermatozoa), compared to the control sample (36.91 nmol/10 ${ }^{9}$ spermatozoa). In a similar experiment conducted by Jones and Mann (1976), the MDA content of ram semen incubated in the presence of $4 \mathrm{mg}$ tocopherol (not tocopherol acetate!) was found to be substantially lower $\left(\sim 5 \mathrm{nmol} / 10^{9}\right.$ spermatozoa) than that of the control semen $(116 \mathrm{nmol} /$ $10^{9}$ spermatozoa). According to Weichet (1965), the marked efficacy difference found between tocopherol and tocopherol acetate is due to the fact that the antioxidant effect markedly decreases during the esterification of tocopherol.

In the 9-day conservation experiment, the quality of semen deteriorated in all samples, irrespective of the treatments. The ratio of spermatozoa with membrane damage increased and sperm motility decreased. Other authors (Maxwell and Salamon, 1993) also observed that the quality of semen deteriorates during storage, irrespective of the extender, the dilution rate, the storage temperature and the storage conditions. Maxwell and Stojanov (1996) demonstrated that acrosome integrity decreases with the lengthening of storage time $(\mathrm{P}<0.01)$, and that there is a significant negative correlation between storage time and the motility of spermatozoa $(\mathrm{P}<0.001)$. 
In the present study, the motility of spermatozoa in semen samples not containing antioxidant significantly decreased $(\mathrm{P}<0.01)$ from the 3rd day of storage as compared to values measured for fresh semen. The ratio of damaged spermatozoa substantially increased from the 2 nd day of storage $(\mathrm{P}<0.01-\mathrm{P}<0.001)$.

In agreement with earlier observations (Shannon and Curson, 1982; Vishwanath et al., 1994; Maxwell and Stojanov, 1996), we found that the addition of antioxidants prolongs the conservation period of semen, improves the motility of spermatozoa and reduces the degree of cell damage. As compared to the 0-hour values, in the treated samples a significant decrease in sperm motility occurred only on the 6th day $(\mathrm{P}<0.05)$. A marked increase in the number of spermatozoa with acrosomal damage occurred only from day 2 in the samples treated with RAR $(\mathrm{P}<0.01)$ and RE $(\mathrm{P}<0.05-0.001)$ and only from day $8(\mathrm{P}<0.01)$ and day $9(\mathrm{P}<0.001)$ in the samples treated with $\mathrm{R}$.

As demonstrated by the TBA reactions, resveratrol, a compound previously not used in semen conservation, proved to be a highly powerful antioxidant. It inhibited lipid peroxidation the most effectively even when applied in a low concentration $\left(15 \mu \mathrm{g} / 10^{9}\right.$ spermatozoa; Fig. 1$)$.

The high efficacy of resveratrol was proved by the similarly good results obtained with its mixtures (RAR, RGP, RE) (Fig. 2). Increasing the concentration of resveratrol to $20 \mu \mathrm{g}$ did not change the MDA content of samples. In conservation tests performed in preliminary experiments not reported here, the motility and acrosome integrity results of semen samples treated with $15 \mu \mathrm{g}$ and $20 \mu \mathrm{g}$ doses of resveratrol were nearly identical. Also in the present semen conservation study, the best results were obtained with resveratrol and with the mixture of resveratrol with Aromex ${ }^{\circledR}$, another antioxidant previously not used in semen conservation (Tables 1 and 2).

On the basis of the results obtained in these experiments it can be concluded that resveratrol is a powerful antioxidant, which has superior activity when applied as a mixture with Aromex ${ }^{\circledR}$. Further studies are needed to determine whether resveratrol can provide even better results in combination with some other antioxidants not tested in this study. In any case, the results obtained in this work may contribute to increasing the freezability of ram semen.

\section{References}

Abu-Erreish, G., Magnes, L. and Li, T. K. (1978): Isolation and properties superoxide dismutase from ram spermatozoa and erythrocytes. Biol. Reprod. 18, 554-560.

Aitken, R. J. and Clarkson, J. S. (1988): Significance of reactive oxygen species and antioxidants in defining the efficacy of sperm preparation techniques. J. Androl. 9, 367-376.

Beconi, M. T., Affranchino, M. A., Schang, L. M. and Beorlegui, N. B. (1991): Influence of antioxidants on SOD activity in bovine sperm. Biochemistry International 23, 545-553.

Beconi, M. T., Francia, C. R., Mora, N. G. and Affranchino, M. A. (1993): Effect of natural antioxidants on frozen bovine semen preservation. Theriogenology 40, 841-851. 
Burcham, P. C. (1998): Genotoxic lipid peroxidation products: their DNA damaging properties and role in formation of endogenous DNA adducts. Mutagenesis 13, 287-305.

Cerovsky, J. (1976): Metoda barveni kancich spermií pro morfologické hodnoceni. Zivocisná Vyroba 21, 361-366.

Cheeseman, K. H. (1993): Mechanism and effects of lipid peroxidation. Mol. Asp. Med. 14, 191-197.

Diplock, A. T. and Lucy, J. A. (1973): The biochemical mode of action of vitamin E and selenium: a hypothesis. FEBS Lett. 29, 205-210.

Dorman, H. J. D., Deans, S. G., Noble, R. C. and Surai, P. (1995): Evaluation in vitro of plant essential oils as natural antioxidants. J. Essent. Oil Res. 7, 645-651.

Gábor, Gy. and Szász, F. (2000): New technologies for testicular and semen assessment. In: Abstract book of the 2nd Meeting of the Association of Applied Animal Andrology, September 26, Milwaukee, WI, USA.

Hammerstedt, R. H. (1993): Maintenance of bioenergetic balance in sperm and prevention of lipid peroxidation: a review of the effect on design of storage preservation systems. In: Sperm Preservation and Encapsulation. Reprod. Fertil. Dev. 5, 675-690.

Jones, R. and Mann, T. (1976): Lipid peroxides in spermatozoa; formation, role of plasmalogen, and physiological significance. Proc. R. Soc. Lond. B. Biol. Sci. 193, 317-333.

Jones, R. and Mann, T. (1977a): Damage to ram spermatozoa by peroxidation of endogenous phospholipids. J. Reprod. Fertil. 50, 261-268.

Jones, R. and Mann, T. (1977b): Toxicity of exogenous fatty acid peroxides towards spermatozoa. J. Reprod. Fertil. 50, 255-260.

Jones, R., Mann, T. and Sherins, R. J. (1978): Adverse effects of peroxidized lipid on human spermatozoa. Proc. R. Soc. Lond. B. Biol. Sci. 201, 413-417.

Kelso, K. A., Redpath, A., Noble, R. C. and Speake, B. K. (1997): Lipid and antioxidant changes in spermatozoa and seminal plasma throughout the reproductive period of bulls. J. Reprod. Fertil. 109, 1-6.

Kovács, A. and Foote, R. H. (1992): Viability and acrosome staining of bull, boar and rabbit spermatozoa. Biotechn. Histochem. 67, 119-124.

Mann, T. (1964): The Biochemistry of Semen and of the Male Reproductive Tract. Methuen, London.

Mann, T. and Lutwak-Mann, C. (1981): Male Reproductive Function and Semen. Springer-Verlag, New York.

Maxwell, W. M. C. and Salamon, S. (1993): Liquid storage of ram semen: a review. Reprod. Fertil. Dev. 5, 613-638.

Maxwell, W. M. C. and Stojanov, T. (1996): Liquid storage of ram semen in the absence or presence of some antioxidants. Reprod. Fertil. Dev. 8, 1013-1020.

Milovanov, V. K., Varnavskij, A. N. and Varnavskaja, V. A. (1976): Method of deep freezing of ram semen for long-term storage (in Russian). Zhivotnovodstvo 8, 57-65.

Nauk, V. A. and Boronchuk, G. V. (1992): Effectiveness of antioxidants in freezing of ram semen (in Russian). Buletinul Academiei de Stiinte a Republicii Moldova. Stiinte Biologice si Chimice 1, 43-46.

Placer, Z. A., Cushman, L. L. and Johnson, B. C. (1966): Estimation of product of lipid peroxidation (malonyl dialdehyde) in biochemical systems. Analyt. Biochem. 16, 359-364.

Shajdullin, I. N. (1977): Artificial insemination of ewes with deep-frozen semen (in Russian). Zhivotnovodstvo. 8, 58-61.

Shannon, P. and Curson, B. (1982): Kinetics of the aromatic l-amino acid oxidase from dead bovine spermatozoa and the effect of catalase on fertility of diluted bovine semen stored at $5^{\circ} \mathrm{C}$ and ambient temperatures. J. Reprod. Fertil. 64, 463-467.

Upreti, G. C., Jensen, K., Oliver, J. E., Duganzich, D. M., Munday, R. and Smith, J. F. (1997): Motility of ram spermatozoa during storage in a chemically-defined diluent containing antioxidants. Anim. Reprod. Sci. 48, 269-278.

Varnavskij, A. N. and Varnavskaja, V. A. (1976): Results of artificial insemination with frozen semen (in Russian). Ovtsevodstvo 9, 19-20. 
Varnavskij, A. N. and Varnavskaja, V. A. (1978): Formulation of a protectant for deep freezing of ram semen (in Russian). Zhivotnovodstvo 9, 65-67.

Varnavskij, A. N. and Varnavskaja, V. A. (1980): Improvement of the method of freezing semen (in Russian). Zhivotnovodstvo 10, 52-53.

Weichet, J. (1965): Tocoferole. In: Fragner, J. (ed.) Vitamine Chemie und Biochemie Band II. G. Fischer Verlag, Jena. pp. 1530-1607.

Vishwanath, R., Munday, R. and Shannon, P. (1994): Field trials on the efficacy of Desferal - a chelating agent - in extending fertilising ability of bull sperm diluted in ambient temperature diluent. In: Proceedings of the New Zealand Embryo Transfer Workshop, ImmunoChemical Products, Auckland. p. 72.

Witting, L. A. (1980): Vitamin E and Lipid Antioxidants in Free-Radical-Initiated Reactions. In: Prior, W. A. (ed.) Free Radicals in Biology. Vol. IV. Academic Press, New York. pp. 295-319. 